\title{
ARTRORESONANCIA: CONCEPTOS GENERALES, INDICACIONES Y RENDIMIENTO
}

\author{
Drs. Gonzalo Delgado $P^{(1,2)}$, Enrique Bosch $\mathrm{O}^{(1)}$, Pablo Soffia $\mathbf{S}^{(1)}$.
}

1. Servicio de Tomografía Computada y Resonancia Magnética. Departamento de Imágenes, Clínica Alemana, Santiago.

2. Servicio de Radiología, Hospital del Trabajador. Santiago.

Abstract: The arthroMR is useful tool in the diagnosis of some intraarticular pathologic conditions, being the gold standard in some of them. This article reviews the technical aspect of this method with regard to the procedure and its main indications and accuracy in the different disorders.

Key words: MRarthrography, MRI.

Resumen: La artroresonancia es un método de diagnóstico por imagen que ha mostrado ser de utilidad en la evaluación de algunas condiciones intraarticulares, considerándose el estándar de referencia en algunas de ellas. Este artículo revisa los aspectos técnicos, en relación al procedimiento propiamente tal, así como sus principales indicaciones, haciendo referencia a su rendimiento en las diferentes patologías.

Palabras claves: Artroresonancia, Resonancia magnética.

\section{Introducción}

El aumento de líquido articular muchas veces facilita la visualización de estructuras intraarticulares y la detección de condiciones patológicas que lo acompañan.

La Artroresonancia (ArtroRM) es un método semiinvasivo de diagnóstico por imagen en donde se distiende la cavidad articular por medio de una punción articular e inyección de contraste paramagnético. Es importante aclarar que este método es llamado también artroresonancia directa para diferenciarlo de la artroresonancia indirecta, que consiste en una inyección de contraste paramagnético vía endovenosa previo al estudio de RM articular. La técnica, «indirecta», sin embargo, presenta una gran limitante que es no producir una

Delgado G, y cols. Artrorresonancia: Conceptos generales, indicaciones y rendimiento. Rev Chil Radiol 2005; 11:75-80. Correspondencia: Dr. Gonzalo Delgado P.

E-mailgdelgado@alemana.cl necesaria distensión articular, la que se obtiene siempre con la técnica directa.

Este artículo revisa aspectos generales de la técnica, indicaciones y rendimiento de la artroresonancia directa.

\section{Técnica}

El examen consta de dos partes fundamentales; la primera corresponde a la inyección intra-articular del contraste paramagnético, y la segunda a la obtención de las imágenes.

La punción articular se realiza bajo radioscopía usando técnica específica para cada articulación, las que no serán motivo de esta revisión. En términos generales, se comprueba la adecuada posición intraarticular de la aguja con una pequeña cantidad de contraste yodado (Figura 1). Posteriormente se inyecta el contraste paramagnético usando dilución de gadolinio. Una dilución adecuada y recomendada es de 1 a 2 cc de gadolinio en 200-250 cc de suero fisiológico, con lo cual se obtiene una concentración de aproximadamente 0.5 - $2 \mathrm{mmo} / \mathrm{l}$.

Las cantidades necesarias para la adecuada distensión en cada articulación se resumen en la Tabla I.

Tabla I. Volumen de dilución de contraste para cada articulación.

Articulación

Cantidad (ml)

Hombro $13-15$

Cadera

$12-14$

Rodilla

$15-20$

Tobillo

6 - 8

Muñeca

$2-3$ 


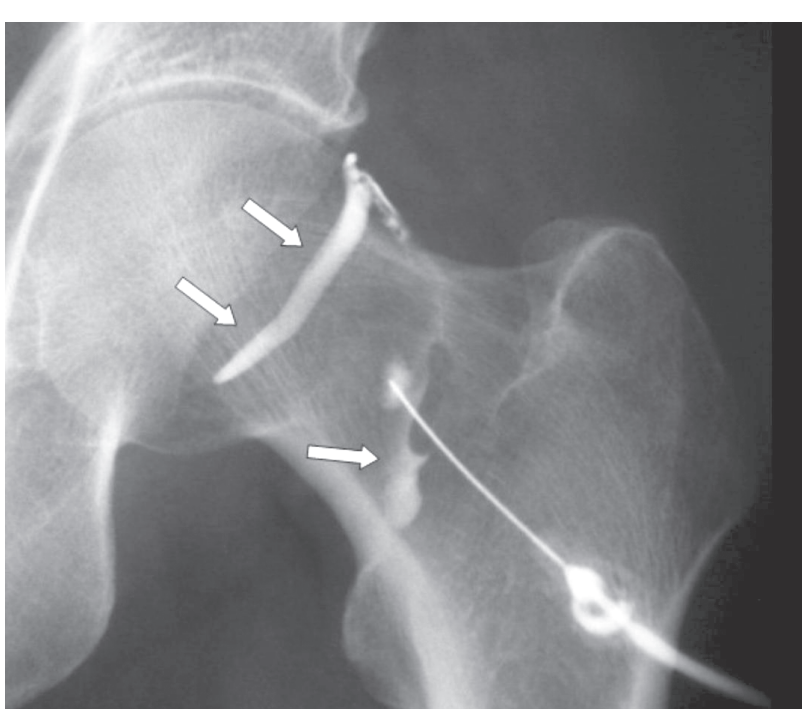

Figura 1. Punción articular de cadera. El contraste yodado (flechas) confirma la ubicación intraarticular de la aguja.

Terminado el procedimiento, el paciente es trasladado a la unidad de resonancia. Es importante no dejar pasar más de 20-30 minutos después de la inyección para que no se produzca una indeseada reabsorción del contraste. Aunque en nuestra experiencia no lo hacemos, algunos centros utilizan adrenalina intraarticular para prevenir este fenómeno.

El protocolo básico del estudio de resonancia, en general, consta de secuencias T1 habitualmente con supresión de la grasa en los tres planos convencionales; axial, coronal y sagital, en donde la dilución de gadolinio tiene alta señal. Es necesario también incluir en al menos un plano una secuencia potenciada en T2, con el objeto de hacer evidente alguna alteración no evidente en T1, como por ejemplo la presencia de gangliones quísticos periarticulares.

Como todo método tiene ventajas y desventajas, algunas de las cuales se indican a continuación:

Ventajas: Mejor visualización de estructuras intraarticulares, evaluación de condiciones donde la RM simple es limitada, realizar diagnósticos que eran propiedad de la artroscopía.

Desventajas: Es un método semiinvasivo (punción articular), necesita de apoyo fluoroscópico, aumento del costo y tiempo de examen respecto de RM simple.

\section{Indicaciones generales}

Existen indicaciones generales e indicaciones particulares para cada articulación.

En los textos de radiología osteoarticular existen listas de posibles indicaciones generales de artroRM, dentro de las cuales es importante señalar tres de ellas:

1. Evaluación de cuerpos libres intraarticulares

2. Evaluación de lesiones osteocondrales para definir su condición de lesión estable versus inestable.
3. Evaluación del cartílago articular.

En el caso de los cuerpos intraarticulares, más que una indicación propiamente tal, podemos encontrar en algunos casos, que el estudio de artroRM referido por alguna otra razón nos permite visualizar con facilidad un cuerpo intraarticular que ha pasado desapercibido en otros estudios de imágenes (Figura 2).

En la evaluación de lesiones osteocondrales es importante para el clínico tratar de definir si la lesión es estable o inestable; en palabras simples, tratar de definir si el cartílago que recubre la lesión esta indemne o fisurado, puesto que la conducta a seguir es distinta. Si el cartílago está discontinuo la lesión es de tipo inestable y podría requerir cirugía.

Con resonancia simple aunque existen algunos signos fundamentalmente indirectos, para definir la posibilidad de inestabilidad del fragmento, la evaluación es difícil y no pocas veces nos quedamos con grandes dudas al respecto. La distensión de la cavidad articular hará más fácil evaluar el estado del cartílago articular. Si está discontinuo permitirá el paso de contraste intraarticular, visualizándose como alta señal en el lecho de la lesión indicando su inestabilidad (Figura 3).

Es más fácil evaluar el cartílago articular, en presencia de aumento de líquido intraarticular, como por ejemplo cuando hay derrame. Aunque no es una indicación propiamente tal, los estudios de artroRM mejoran su evaluación. Esto tiene relación también con lo descrito previamente para las lesiones osteocondrales.

Las indicaciones particulares de cada articulación las revisaremos a continuación, por separado.

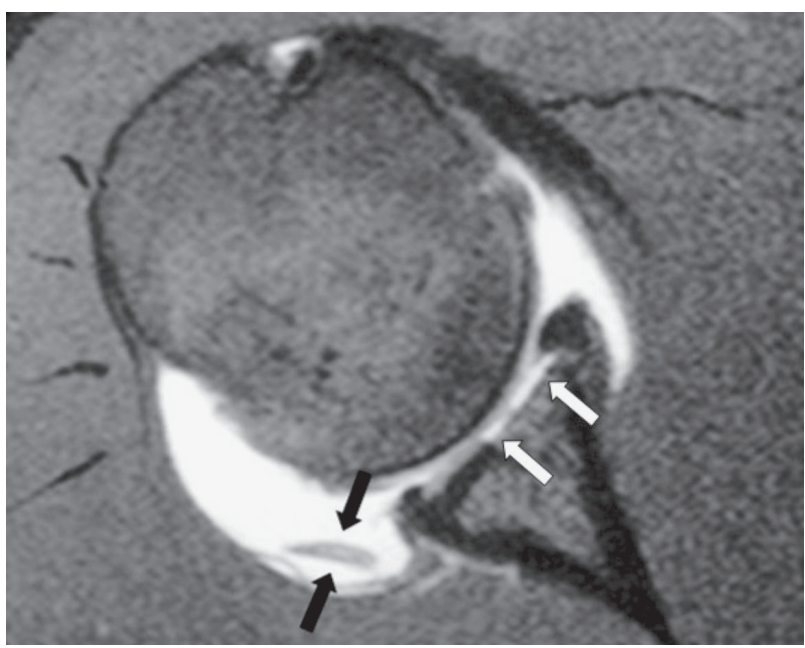

Figura 2. ArtroRM de hombro que muestra un fragmento osteocondral intraarticular (flechas negras). Se puede identificar el sitio donante en la glenoides (flechas blancas). 


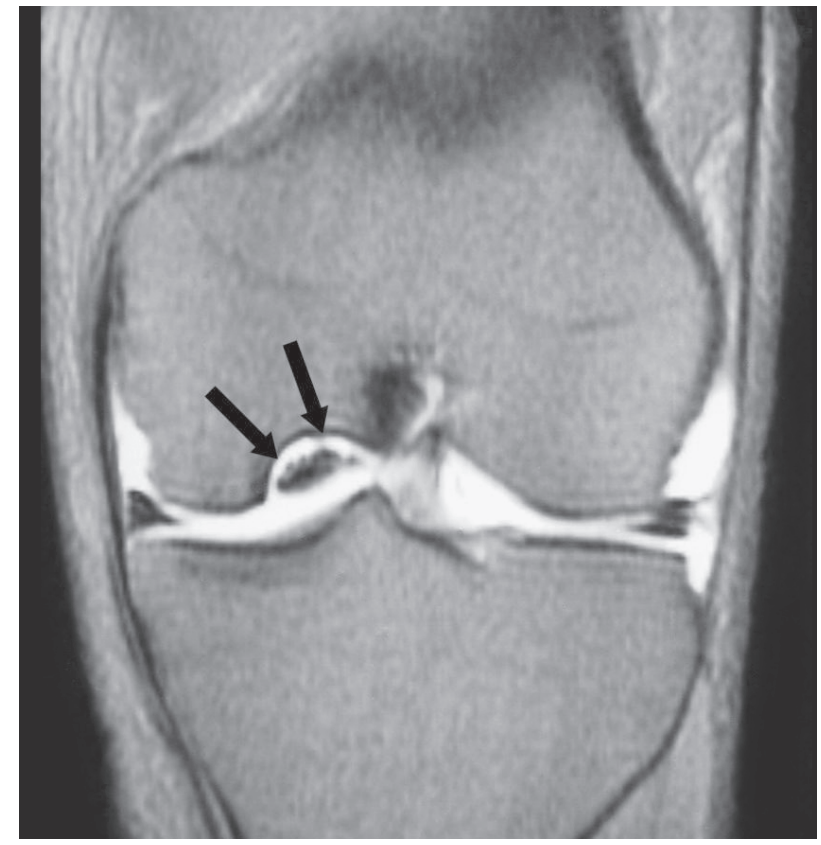

Figura 3. Osteocondritis disecante del cóndilo femoral interno. El gadolinio intraarticular (flechas) ha penetrado en el lecho de la lesión, lo que demuestra inestabilidad.

\section{Hombro}

En el hombro las principales indicaciones de artroRM son la evaluación de lesiones del labrum glenoideo y ligamentos gleno-humerales. En este sentido las inestabilidades de hombro, especialmente secundarias a eventos únicos o repetidos de luxación anterior, son una de las principales causas de lesiones labro-ligamentosas. La lesión clásica como secuela de luxación anterior es la rotura o desinserción del labrum anterior en su tercio inferior, también conocida como lesión de Bankart cartilaginosa, para diferenciarla de la lesión de Bankart ósea, que corresponde a una fractura del margen óseo glenoideo antero-inferior (Figura 4).

Por otro lado, también existen lesiones labroligamentosas que no se asocian a secuelas de luxaciones. Como ejemplo mencionaremos la lesión de SLAP (lesión de labrum superior de anterior a posterior), que se asocia a algunas actividades deportivas, especialmente aquellas donde se efectúan lanzamientos y movimientos repetidos y forzados de la extremidad superior por sobre el nivel de la cabeza, como en el béisbol, tenis, vóleibol, etc. (Figura 5).

En algunos centros de Norteamérica la evaluación de inestabilidad anterior de hombro es siempre con artroRM. En un estudio en 121 pacientes con inestabilidad de hombro tuvo una sensibilidad y especificidad del $92 \%$ en la detección y caracterización de lesiones de labrum glenoideo tipo Bankart ${ }^{(1)}$. En una publicación reciente se reporta una sensibilidad de $82 \%$ y especificidad de $98 \%$ en la detección de lesiones tipo SLAP(2).

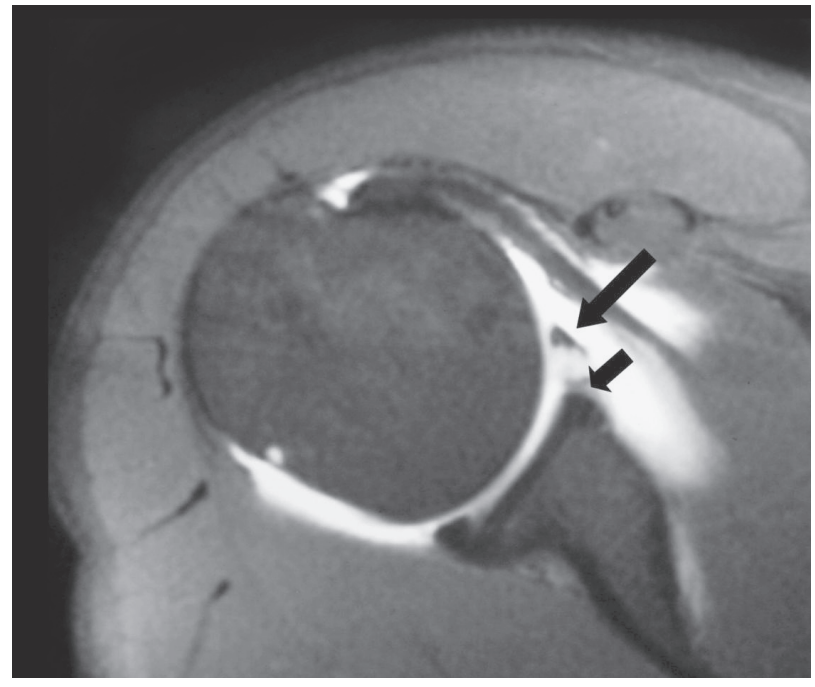

Figura 4. ArtroRM de hombro demostrando desinserción del labrum anterior (flechas) compatible con lesión de Bankart cartilaginoso.

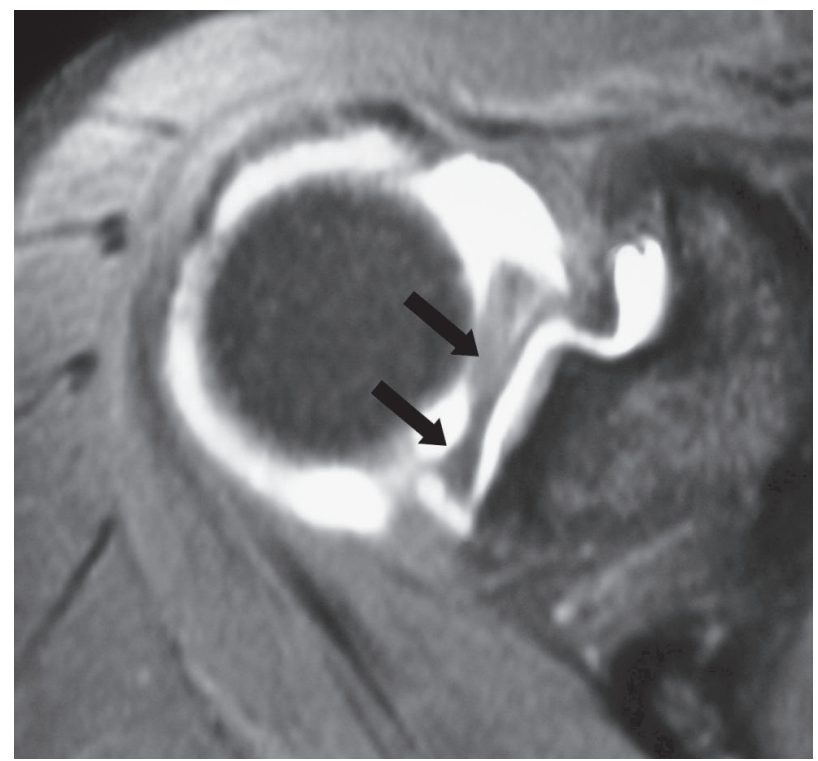

Figura 5. ArtroRM de hombro demostrando desinserción del labrum superior (flechas) compatible con lesión tipo SLAP.

\section{Cadera}

En la cadera la principal indicación es la evaluación del labrum acetabular, habitualmente en pacientes con sospecha de síndrome de pellizcamiento femoroacetabular anterior. Este síndrome se presenta en adultos jóvenes, con dolor referido a la región inguinal. Al examen físico destaca la presencia de dolor a la rotación interna de la cadera cuando está en flexión de $90^{\circ}$. Se ha propuesto dentro de las causas una prominencia ósea conocida como «bump» a nivel de la cara anterior en la zona de unión de cabeza y cuello femoral (Figura 6). La porción antero-superior del labrum es la que se 
lesiona con más frecuencia en estos pacientes. La lesión puede consistir en rotura o desinserción. La rotura se puede evidenciar como ausencia de la estructura normal del labrum (Figura 7) o identificarse como una imagen lineal en el espesor de este fibrocartílago (Figura 8). La desinserción se manifiesta como una separación anormal del labrum con respecto al reborde óseo acetabular (Figura 9).

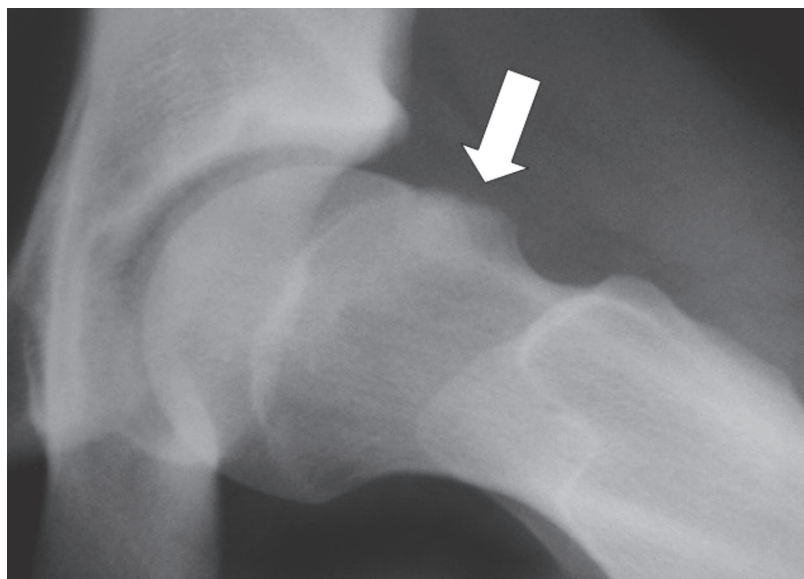

Figura 6. Radiografía de cadera, proyección axial mostrando prominencia ósea a nivel de unión de cabeza y cuello femoral (flecha), alteración conocida como «bump».

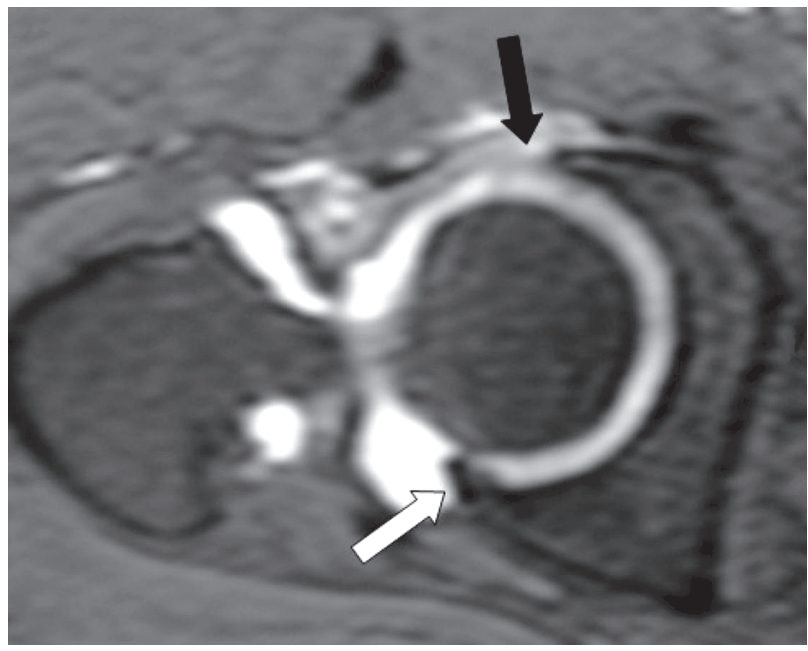

Figura 7. ArtroRM de cadera mostrando ausencia de labrum anterior compatible con rotura (flecha negra). El labrum posterior (flecha blanca) se reconoce de estructura normal.

\section{Rodilla}

En rodilla la principal indicación es la evaluación de re-roturas o roturas remanentes en meniscos que han sido previamente operados con meniscectomía parcial. La evaluación de roturas residuales o re-roturas en meniscos operados es limitada con el uso de RM simple, si se compara con artroRM ${ }^{(3)}$; el problema se basa en que en la primera los meniscos operados pueden mostrar alteraciones de señal dado por cambios postquirúrgicos, que

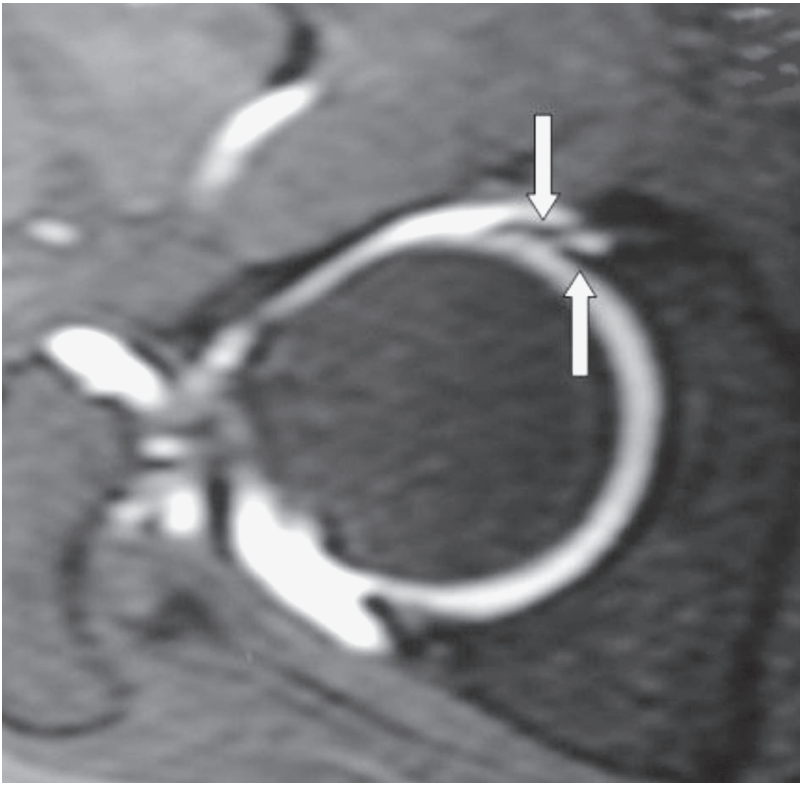

Figura 8. ArtroRM de cadera con imagen de rotura de labrum anterior (flechas).

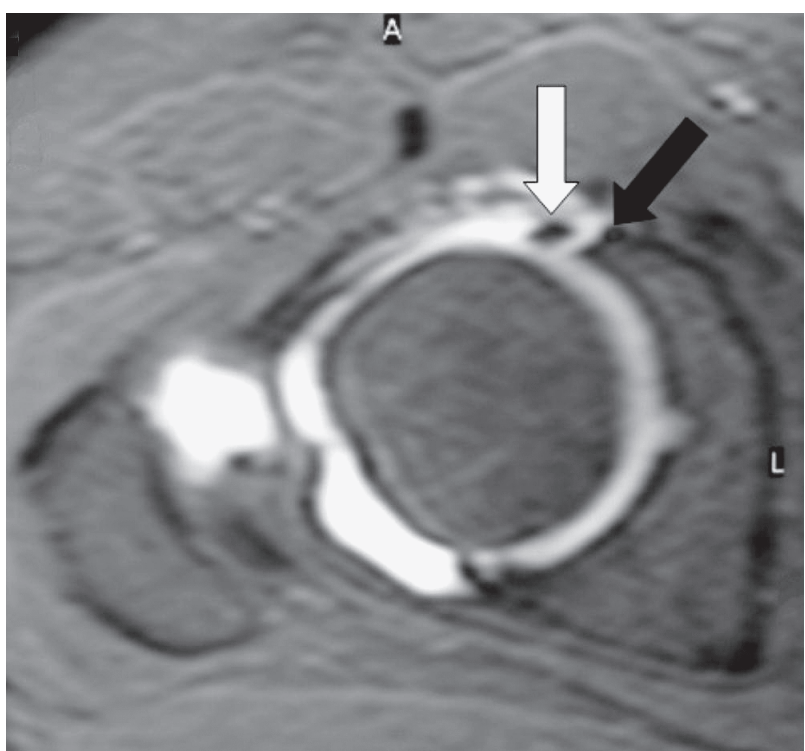

Figura 9. ArtroRM de cadera que muestra desinserción de labrum anterior (flecha blanca) el que se observa separado del reborde óseo del acetábulo (flecha negra).

podrían hacer pensar en nueva rotura. Una alteración de señal que en un menisco sin cirugía es patognomónica de rotura, en un menisco resecado parcialmente no necesariamente corresponde a rotura. Algunos autores han mostrado buen rendimiento de la RM simple, sin embargo, siempre inferior a la $\operatorname{artroRM}^{(4)}$.

El hallazgo de contraste en el espesor del remanente meniscal es compatible con re-rotura o rotura remanente (Figura 10). 


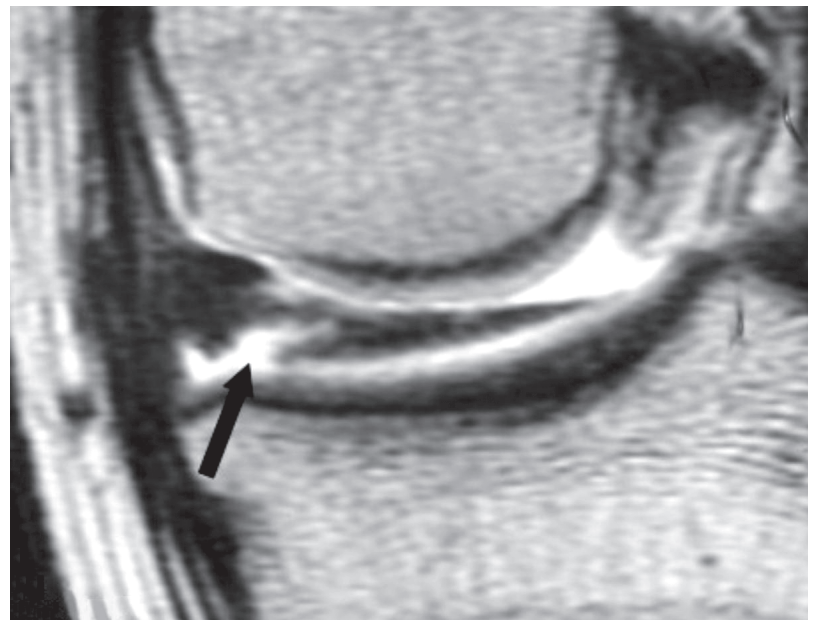

Figura 10. ArtroRM de rodilla en paciente con lesión de menisco reparada con sutura. El examen muestra rotura residual (flecha).

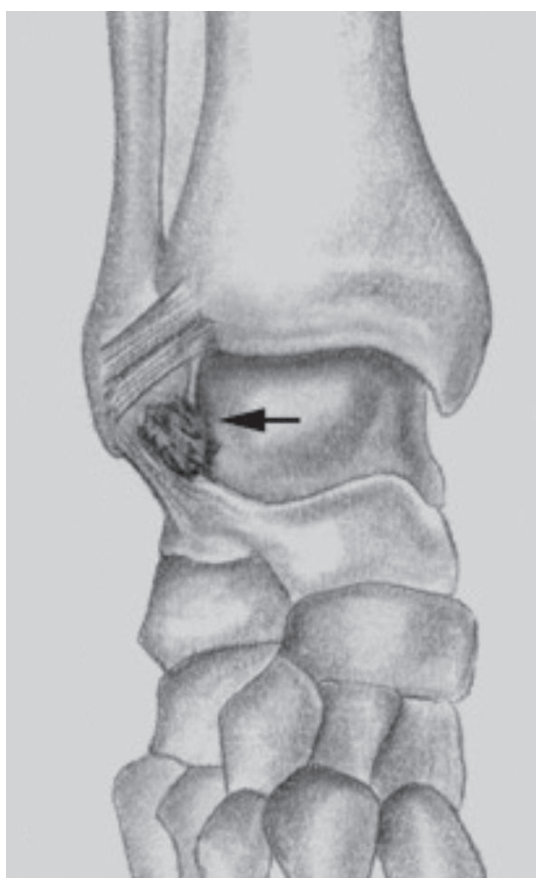

Figura 11.

Esquema

mostrando nódulo de partes blandas (flecha) visible en casos de pellizcamiento antero-lateral. Modificado de Am $J$ Roentgenol AJR, 2003; 181: 551

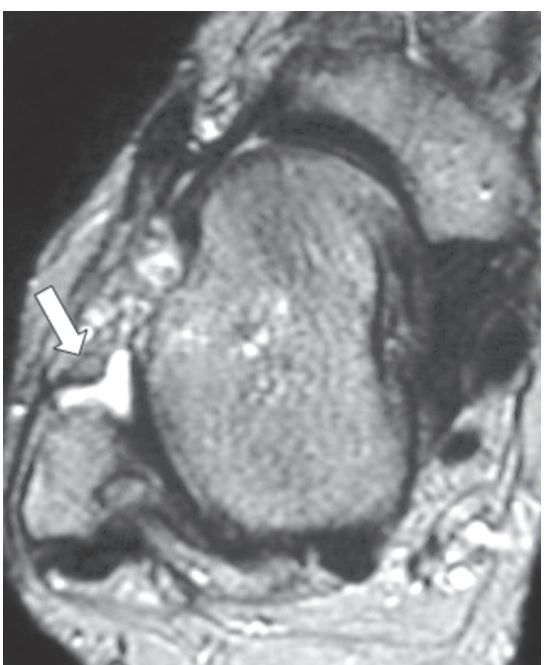

Tobillo

En el tobillo es el síndrome de pellizcamiento antero-lateral o síndrome meniscoide la condición más frecuentemente referida para estudio con artroRM. Esta entidad es causa de dolor crónico lateral y tiene relación con eventos previos de esguince de ligamentos colaterales laterales. La clave es identificar un engrosamiento nodular o irregular en el plano capsulo-sinovial del receso antero lateral (Figura 11), que se correlaciona con la presencia de un área de sinovitis crónica focal a la artroscopía.

La RM simple es de limitada utilidad en esta condición $^{(5)}$ a excepción de los casos en donde incidentalmente se observa líquido intraarticular en el receso antero-lateral que permite evaluar el plano capsulo-sinovial (Figura 12). La artroRM ha mostrado excelentes resultados en la evaluación de estos pacientes con sensibilidad de $96 \%$ y especificidad de $100 \%{ }^{(6)}$.

\section{Muñeca}

Las dos indicaciones en esta articulación son: la evaluación de roturas del fibrocartílago triangular (FCT) y las lesiones de los ligamentos interóseos de la primera fila del carpo (escafo-lunar y lunotriquetral). La evaluación de ambas condiciones no es fácil con RM simple ${ }^{(7)}$, mostrando la artroRM bastante mejor rendimiento ${ }^{(7,8)}$. El contraste intraarticular en la muñeca ayuda considerablemente en la evaluación anatómica de estas estructuras y sus lesiones (Figuras 13,14).

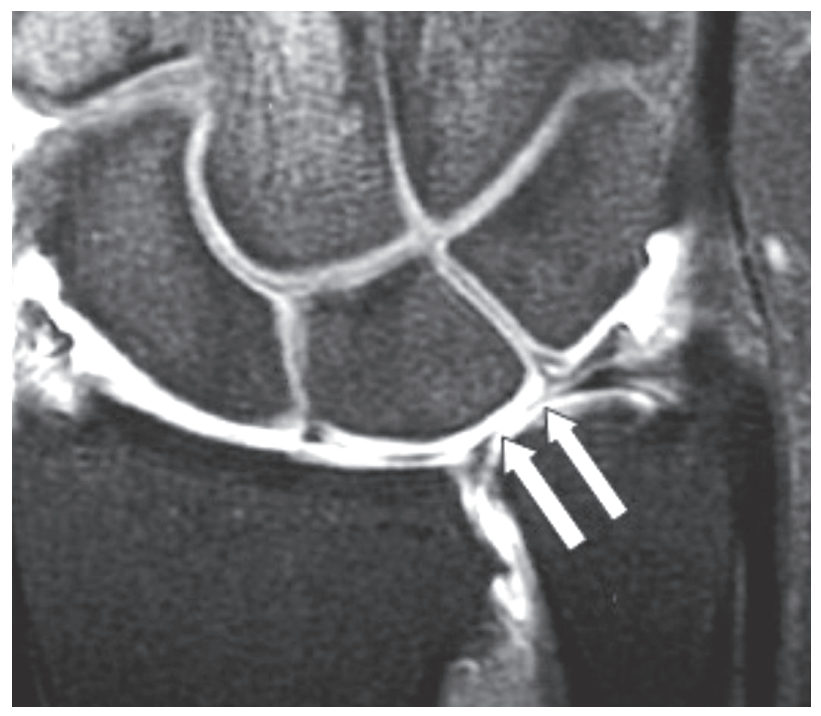

Figura 13. ArtroRM de muñeca mostrando rotura del FCT (flechas).

Figura 12. RM simple de tobillo con secuencia T2 mostrando leve cantidad de líquido en receso anterolateral, que permite visualizar un nódulo de partes blandas compatible con pellizcamiento antero-lateral. 


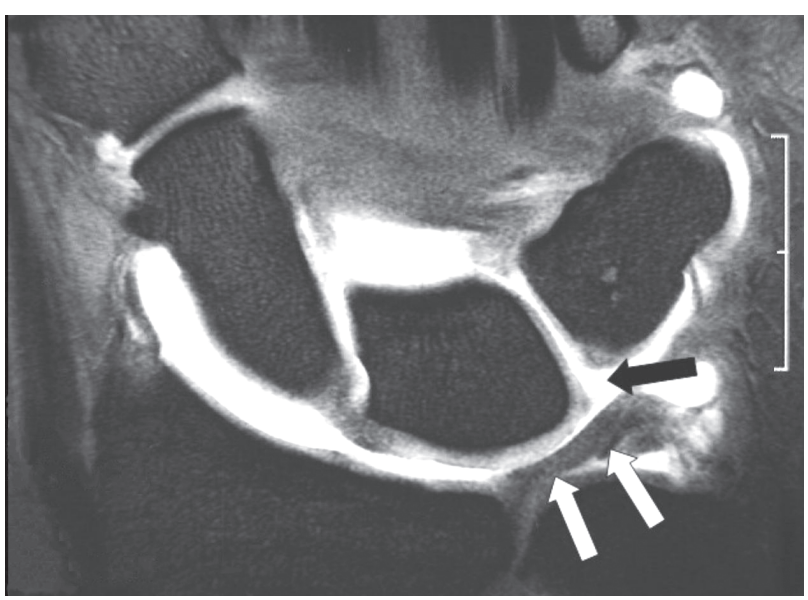

Figura 14. ArtroRM de muñeca que muestra rotura de ligamento luno-triquetral (flecha negra). EI FCT se demuestra indemne (flecha blanca).

\section{Conclusión}

En resumen, la artroRM es un método que tiene excelente rendimiento e indicaciones precisas en la evaluación de algunos tipos de lesiones intraarticulares. La evaluación en conjunto por el clínico y radiólogo, de cada caso en particular, será en definitiva la que decidirá el potencial beneficio del paciente, tomando en consideración las ventajas y desventajas de este método.

\section{Bibliografía}

1. Palmer W, Caslowitz P. Anterior shoulder instability: diagnostic criteria determined from prospective analysis of 121 MR arthrograms. Radiology 1995; 197 : 819-825.

2. Waldt $S$, Burkat $A$, Lange $P$, et al. Diagnostic Performance of MR Arthrography in the Assessment of Superior labral Anteroposterior lesion of the shoulder. Am J Roentgenol AJR 2004; 182: 1271-78.

3. Sciulli RL, Boutin RD, Brown RR, et al. Evaluation of the postoperative meniscus of the knee. Skeletal Radiology 1999; 28: 508-14.

4. White LM, Schweitzer ME, Weishaupt D. et al. Diagnosis of recurrent meniscal tears: prospective evaluation of conventional MR imaging, indirect MR arthrography, and direct MR arthrography. Radiology 2002; 222: 421-429.

5. Rubin D, Tishkoff N, Britton C, Conti S, Towers J. Anterolateral soft-tissue impingement in the ankle: diagnosis using MR imaging. AJR 1997; 169: 829-835.

6. Robinson P, White L, Salonen D, Daniels T, OgilvieHarris D. Anterolateral ankle impingement. MR arthrographic assessment of the anterolateral recess. Radiology 2001; 221: 186-190.

7. Scheck R, Kubitzek C, Hierner R. et al. The scapholunate interosseous ligament in MR arthrography of the wrist: correlation with nonenhanced MRI and wrist arthroscopy. Skeletal radiology, 1997: 26; 263-71.

8. Schmitt R, Christopoulos G, Meier R. et al. ROFO 2003; 175: 911-19. 